\title{
Bullying Among Middle School Students with Disabilities
}

\author{
Breanna McNeal ${ }^{1}$ and Dorothy Espelage, Ph.D. ${ }^{2}$ \\ ${ }^{1}$ College of Liberal Arts and Sciences, University of Florida \\ ${ }^{2}$ Department of Psychology, University of Florida
}

Faculty mentor: Dorothy Espelage, Department of Psychology

\begin{abstract}
This investigation examined the association between bully victimization and willingness to intervene in bullying situations among students with and without disabilities. Through the use of self-report surveys, middle school students $(n=1005)$ participated in the study. The majority of students with disabilities reported having a Specific Learning Disability, and the sample included 49\% male students and 44\% Caucasian students. Results indicated that there was no significant effect for disability status on willingness to intervene; however, students who were bullied were more willing to intervene compared to youth with low rates of victimization. Students with disabilities who were victimized at high rates reported greater willingness to intervene in bullying situations compared to students with disabilities who reported lower rates of victimization and students without disabilities. These findings suggest that students with disabilities play a critical role in supporting other students who are being victimized by intervening to help them.

Keywords: bullying, middle school, disabled children,
\end{abstract}

\section{Introduction}

Bullying has been and continues to be a major problem and health concern in schools today (Rose, Simpson, \& Preast, 2016, 308). In a national survey, 20\% of high school students admitted to being bullied over the prior year (Centers for Disease Control and Prevention, 2017). The Centers for Disease Control and Prevention (2017) and National Institute of Justice (2016) define bullying as "any unwanted aggressive behavior(s) by another youth or group of youths who are not siblings or current dating partners that involves an observed or perceived power imbalance and is repeated multiple times or is highly likely to be repeated."

The mission of schools is to educate students, however, learning and performance can be impacted as students may not be able to give their best effort in school if they are afraid to go to lunch, ride the bus, or attend class (Wolpert, 2010). Therefore, school safety affects the overall well-being of children and adolescents. Victims of bullying face short and long-term social, 
emotional, physical and educational effects as a result of the bullying experienced in school settings (Centers for Disease Control and Prevention, 2017).

\section{Students with Disabilities and Bullying Victimization}

Saylor and Leach (2009, p. 77), along with Rose et al. (2016, p. 314), explain that students with disabilities are more likely to become victims of bullying compared to students without disabilities. Specifically, Blake, Lund, Zhou, Kwok, and Benz (2012) propose that based on the national average, students with disabilities have a 1.5 increased risk of being victimized. Of those who admit to being bullied, about $25 \%$ are students with disabilities in elementary schools, about $34 \%$ are students with disabilities in middle schools, and about $27 \%$ are students with disabilities in high schools (Rose et al., 2016, p. 308).

For example, students with hearing impairments are often bullied by hearing students. However, students with disabilities who are surrounded solely by children and adolescents with the same disabilities are still bullied. In a study on deaf and hearing students, deaf students were bullied by fellow deaf students, and were even more likely to become victims of bullying when associated with hearing students (Weiner \& Miller, 2006). Some children and adolescents with disabilities have not interacted with other students who have the same or similar disabilities prior to beginning school. For instance, about $10 \%$ of deaf students do not have a deaf family member (Weiner \& Miller, 2006). Therefore, deaf students may not have learned sign language or may not have met other children with hearing impairments until they started school. This adjustment can add additional stress when interacting with other students, possibly leading to additional bullying due to the lack of social skills.

In a study by Chen, Hamm, Farmer, Lambert and Mehtaji (2015), they found that just over $33 \%$ (44 out of 327) of the students who began 6th grade were bullied, and about $60 \%$ of the students with disabilities remained victimized in the transition from elementary school to middle school. This level of continued victimization may further explain why the majority of students with disabilities are socially isolated, leaving only about $7 \%$ who fit in well with the student population beginning their first year in middle school. Specifically, in a study by Norwich and Kelly (2004), about $50 \%$ of students with learning difficulties believed they were bullied because of their disabilities. 


\section{Students with Disabilities and Bystander Intervention}

Bystanders are individuals who are present during bullying incidents (Evans \& Smokowski, 2017). There are numerous reactions bystanders could have when witnessing bullying behavior. For example, in a study by Bradshaw, Sawyer and O'Brennan (2007), they found that just over $70 \%$ of students in elementary school, middle school and high school have witnessed some sort of bullying activity. However, of the middle and high school bystanders, the students reported that they did not intervene the bullying behavior. This study supports the findings that it is rare for bystanders to engage in bullying intervention (Macháčková, Dedkova, Sevcikova, \& Cerna, 2013, p. 27).

Specifically, students with disabilities tend to not intervene as bystanders in bullying incidents in order to prevent themselves from being bullied (Macháčková, Dedkova, Sevcikova, \& Cerna, 2013, p. 27). Having disabilities may keep students isolated or prevent them from being socially involved with other children and adolescents, and as a result, they are less likely to intervene (Evans \& Smokowski, 2015, p. 2304). Therefore, this study will analyze if students with disabilities, being especially vulnerable to bullying victimization, will intervene as bystanders in future bullying incidents (Eisenberg, Gower, McMorris, \& Bucchianeri, 2015, p. 1789).

\section{Bullying Victimization and Bystander Intervention}

The effects of being bullied may alter how victims view bullying behavior. Therefore, it is important for the victims to receive counseling on how to process, cope and overcome the effects of bullying in order to improve their self-esteem and social skills (Miller, Beane \& Kraus, 1998). In turn, this may help prevent them from being victimized in the future, and it may open opportunities for them to assist others who are being bullied. Victims of bullying can better relate to other victims of bullying, resulting in an increased desire to intervene bullying incidents (Menesini et al., 1997, p. 247).

After analyzing numerous research studies, the following findings remain consistent: (1) students with disabilities are more susceptible to becoming victims of bullying, (2) students with disabilities tend to not intervene bullying behavior, and (3) bystanders who were once victims of bullying are more likely to intervene bullying incidents.

It was hypothesized that the relation between bullying victimization and willingness to intervene would be moderated by disability status. That is, students with disabilities who 
experienced high rates of victimization would report greater willingness to intervene compared to students without disabilities who experienced high rates of victimization.

\section{Methods}

\section{Sample}

The Dane County Youth Survey was administered to students in schools within Dane County, Wisconsin. After the caregivers gave consent, the students voluntarily completed the survey on computers during school hours. The students' responses were confidential and anonymous. Following completion of the survey, the students had the opportunity to seek counseling services if they experienced mental distress. Due to a high response rate, the data collected was diverse.

\section{Participants}

At baseline, this study examined a total of 1005 students, 10 to 16 years of age $(M=12.98$; $\mathrm{SD}=1.071$ ) from Midwestern middle schools. There were about an even number of males to females, and the majority of students with disabilities reported having a Specific Learning Disability. There were $49 \%$ male, $42 \%$ African-American, and 44\% Caucasian participants. Looking at parental education, the sample seems to have a lower to middle socioeconomic status. Fifty-five students had a documented disability. See Table 1 for demographics.

Table 1. Demographics Frequency Table

\begin{tabular}{lcc}
\hline Variable & $\mathrm{N}$ & Percent \\
\hline Age & & \\
10 & 10 & 1.0 \\
11 & 77 & 7.7 \\
12 & 230 & 22.9 \\
13 & 356 & 35.4 \\
14 & 273 & 27.2 \\
15 & 56 & 5.6 \\
16 & 3 & 0.3 \\
Gender & & \\
Male & 495 & 49.3 \\
Female & 510 & 50.7 \\
Race & & \\
African American & 418 & 41.6 \\
Asian / Pacific Islander & 19 & 1.9 \\
Hispanic & 26 & 2.6 \\
Caucasian & 443 & 44.1
\end{tabular}


Other

Disability

Cognitive Disability

Emotional / Behavioral Disorder

8

Other Health Impairment

$2 \quad 0.2$

Orthopedic Impairment

2

Specific Learning Disability

$30 \quad 3$

Speech / Language Impairment

6

Visual Impairment

2

0.6

Mother's Education

Less than high school

59

255

High school diploma or GED

152

Some college

Some graduate school

Graduate or professional (accountant, doctor, lawyer)

Less than high school

High school diploma or GED

Some college

As part of a larger study, students completed self-report measures on disability, willingness to intervene, and peer victimization. Surveys and interviews were completed in the Spring of 2008 and the Fall of 2008. Parental forms were sent home with each student for parents to sign and return if they did not want their student to participate in the study. Data from the students were collected by a faculty member, the primary researcher and six trained research assistants. The students were presented with information about the study and then measures were taken to ensure the students were seated with enough space in between them to eliminate cheating. The survey questions were read aloud to the students, and the surveys were completed in about 40 minutes.

\section{Measures}

Disability. The students answered whether they have disabilities as it relates to specific educational activities, and if so, whether they are emotional, learning, or physical disabilities. Students chose between "yes" (1) or "no" (0). The type of disability was obtained through official school records. 
Willingness to intervene in bullying episodes. The authors created the University of Illinois Willingness to Intervene in Bullying Episodes specifically for this study. The 5-item scale was developed from a series of interviews and surveys of students in grades 3rd through 8th. The researchers asked students the extent that they agree with statements about intervening directly or indirectly when they encounter bullying (e.g., "If a kid is being teased, I will stick up for him/her.", "I will tell an adult if a kid is being teased a lot."). Response options were "Strongly Disagree", "Disagree”, “Agree”, and "Strongly Agree.” Factor loadings of the five items ranged from .71 through .43 , no cross-loadings on the bully factor were greater than .30. Cronbach's alpha coefficients were .75 for this study.

Physical and verbal aggression victimization. Victimization from peers was assessed using the 4-item University of Illinois Victimization Scale (UIVS; Espelage \& Holt, 2001). Students are asked how often the following things have happened to them in the past 30 days (i.e., "Other students called me names", "Other students made fun of me", "Other students picked on me", and "I got hit and pushed by other students"). Response options include "Never", "1 or 2 times", "3 or 4 times", "5 or 6 times", and "7 or more times." Construct validity of this measure was supported through exploratory and confirmatory factor analyses and convergence with peer nominations of victimization (Espelage \& Holt, 2001). Higher scores indicate more self-reported victimization. A Cronbach's alpha coefficient of .86 was found for the current study.

\section{Data Analytic Plan}

The moderation model assessed the conditional effects of having a disability on the relationship between bully victimization and willingness to intervene in bullying situations (Figure 1 for proposed Moderation Model).

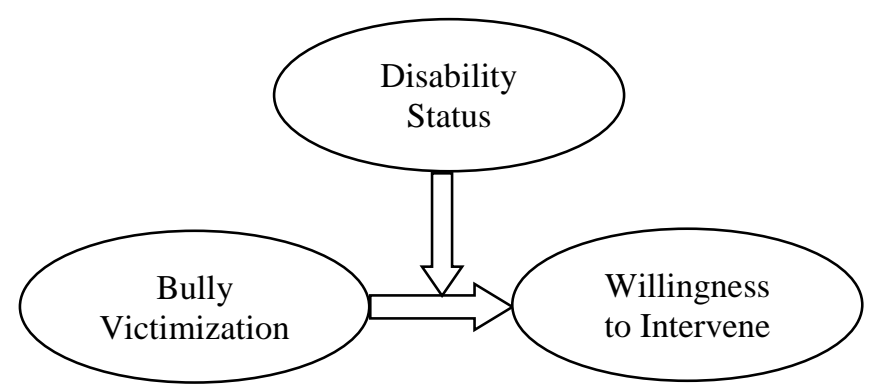

Figure 1. Diagram of moderation model assessing disability status on the association between bully victimization and willingness to intervene. Analysis of variance (ANOVA) was used to test this moderation. The independent variables were disability status ( $1=$ no, $2=$ yes) and bully victimization ( $1=$ low victimization, $2=1 \mathrm{SD}$ above the mean on the bully victimization scale). The outcome variable was willingness to intervene in bullying situations. 


\section{Results}

The authors conducted a two-way ANOVA to examine the predictors of disability status and bully victimization on willingness to intervene. Results indicated no significant effect for disability status on willingness to intervene $(F=3.17, p>.05)$; however, students who were bullied were more willing to intervene compared to youth with low rates of victimization $(F=$ $6.36, p<.01)$. However, this main effect was qualified by a significant interaction between disability status and bullying victimization on willingness to intervene $(F=4.517, p<.05)$. Figure 2 indicates that students with disabilities who were victimized at high rates reported greater willingness to intervene in bullying situations compared to students with disabilities who reported lower rates of victimization and students without disabilities. Possible explanations of this finding may include increased levels of empathy or confidence to support bullying victims due to prior victimization.

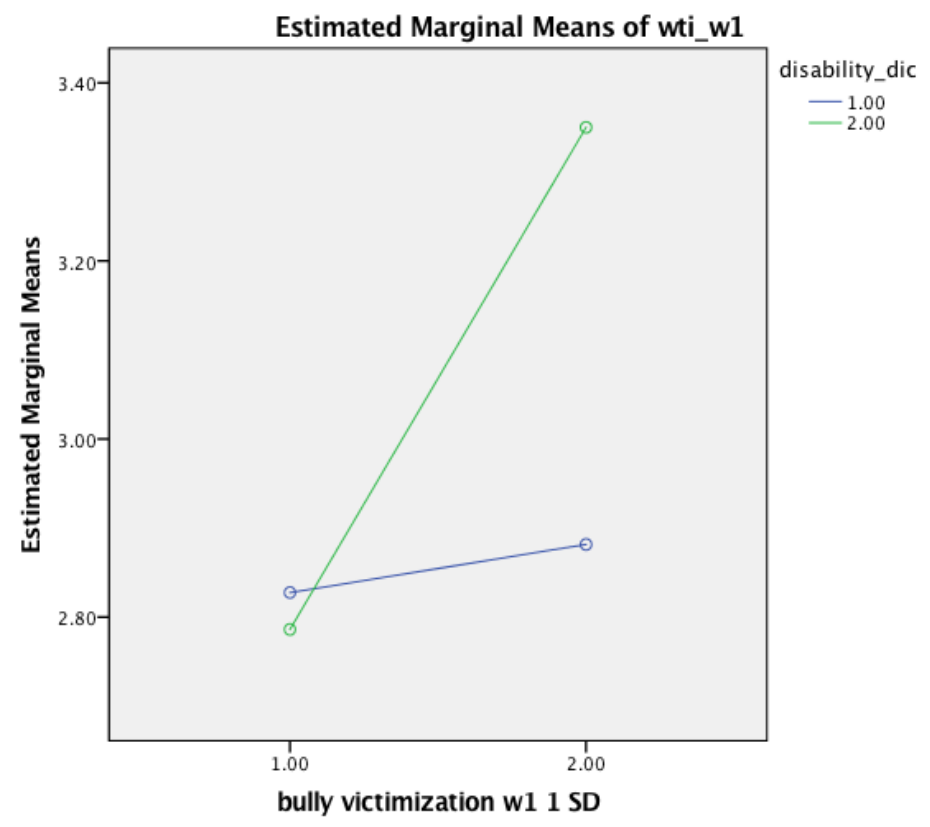

Figure 2. Moderation effect of disability status on the association between bully victimization and willingness to intervene in bullying situations 
Table 2. Correlation Matrix

\begin{tabular}{|c|c|c|c|c|c|c|c|c|}
\hline Measure & 1 & 2 & 3 & 4 & 5 & 6 & 7 & 8 \\
\hline 1. Age (years) & & $-.07 *$ & $-.10 * *$ & .05 & -.01 & $-.08 *$ & $-.15 * *$ & $-.19 * *$ \\
\hline 2. Gender & & & .02 & -.03 & -.01 & -.04 & $.26 * *$ & -.01 \\
\hline 3. Race & & & & $.22 * *$ & $.29 * *$ & $.07 *$ & $.15^{* *}$ & -.06 \\
\hline 4. Mother's education & & & & & $.62 * *$ & -.05 & .03 & $-.10^{* *}$ \\
\hline 5. Father's education & & & & & & .01 & $.07 *$ & $-.08 *$ \\
\hline 6. Bully victimization & & & & & & & $.07 *$ & -.02 \\
\hline 7. Intervene when see bullying & & & & & & & & .01 \\
\hline 8. Disability & & & & & & & & \\
\hline
\end{tabular}

\section{Discussion}

The goal of the present study was to examine the correlation among disability status, bully victimization, and willingness to intervene bullying incidents. It was hypothesized that the relation between bullying victimization and willingness to intervene would be moderated by disability status. Overall, the moderation model confirms this hypothesis. The results showed that there was no significant relationship between disability status and willingness to intervene. However, students who were bullied were more willing to intervene. Overall, there was a significant interaction between disability status and bullying victimization on willingness to intervene.

Interestingly, as this study found no significant correlation between disability status and willingness to intervene in bullying situations, previous literature shows that students with disabilities are less likely to intervene (Evans \& Smokowski, 2015). A possible explanation for this may be due to controlled factors such as levels of social interactions or self-esteem. Also, it is important to note that this study confirms previous research claiming that students who have been bullied are more likely to intervene in bullying situations (Menesini et al., 1997). Overall, these results are meaningful and can help guide future research on this topic.

\section{Limitations}

As mentioned above, the data were self-reported through surveys. Therefore, students may have had various viewpoints in how they perceived bullying or intervention behaviors. In addition, the survey responses used for data collection were based on whether the students have disabilities, have been victims of bullying in general, and have intervened in bullying incidents. Therefore, the victims of bullying may not have been bullied because of their disabilities, and the 
intervention behaviors may not have resulted from having disabilities or from being prior victims of bullying. The study was also limited to cross-sectional data and a small number of students with disabilities.

\section{Conclusion}

In addition to collecting data through self-report measures, it would be beneficial to gather teachers' responses about their students' behaviors as it pertains to bullying, victimization, and intervention. Also, it is recommended to set up audio and video recording devices in common locations at various schools, in order to record students' specific actions. Due to the self-report nature of the surveys, incorporating the use of recording devices as well as teachers' responses would allow the behaviors observed to be measured with the same coding criteria in order to reduce the various perspectives of what constitutes bullying and intervention behavior. This would also allow data collection from students with disabilities whose disability prevented them from completing the survey.

Further, it would be useful to incorporate additional survey questions based on whether students were bullied because of their disabilities and why the students were more or less willing to intervene in bullying incidents. Finally, it is recommended to extend the survey question regarding whether the students have been bullied in the past 30 days, to see if the results would remain the same.

\section{Implications}

Counseling interventions, including support groups in school settings, may provide an avenue for students with disabilities who have been victims of bullying to learn from their experiences and be equipped with tools on how to respond should they encounter similar situations in the future. Differences among students should be accepted and valued, and because of the negative effects caused by bullying, effective preventative measures should be taken to ensure schools are safe atmospheres for students. Negative emotional and behavioral impacts of stressors that students with disabilities face while at school are enhanced when they become victims of bullying. (Morrison, Furlong, \& Smith, 1994). In addition, Olweus (1995) explains that it is vital for schools to be places where children and adolescents are welcomed in an atmosphere that is open toward communication on bullying. Changing the overall learning experience is key to this intervention. Therefore, it is important for students, faculty, and staff to be educated on the 
importance of being prosocial active bystanders, leading to better implementation of intervention measures. Overall, students without disabilities and faculty members can gain a greater understanding for the roles they play in providing support for disabled children and adolescents both during and after intervention.

\section{Acknowledgements}

A special thank you to Dr. Dorothy Espelage for her mentorship and guidance. Additional gratitude to Katie Ingram for her assistance and to Dr. Martin Heesacker and Dr. Marina Klimenko for their willingness to serve as committee members.

\section{References}

Blake, J. J., Lund, E. M., Zhou, Q., Kwok, O.-m., \& Benz, M. R. (2012). National prevalence rates of bully victimization among students with disabilities in the United States. School Psychology Quarterly, 27(4), 210-222.

Bradshaw, C. P., Sawyer, A. L., \& O'Brennan, L. M. (2007). Bullying and peer victimization at school: Perceptual differences between students and school staff. School Psychology Review, 36(3), 361382.

Centers for Disease Control and Prevention, "Preventing Bullying Factsheet." (2017). Retrieved January 10, 2018, from https://www.cdc.gov/violenceprevention/pdf/bullying-factsheet.pdf

Chen, C., Hamm, J. V., Farmer, T. W., Lambert, K., \& Mehtaji, M. (2015). Exceptionality and Peer Victimization Involvement in Late Childhood. Remedial \& Special Education, 36(5), 312-324. doi:10.1177/0741932515579242

Eisenberg, M. E., Gower, A. L., McMorris, B. J., \& Bucchianeri, M. M. (2015). Vulnerable bullies: Perpetration of peer harassment among youths across sexual orientation, weight, and disability status. American Journal of Public Health, 105(9), 105(9), 1784-1791. doi:10.2105/AJPH.2015.302704

Espelage, D., \& Holt, M. (2001). Suicidal Ideation and School Bullying Experiences After Controlling for Depression and Delinquency. Journal of Adolescent Health, 53(2013), S27-S31.

Evans, C. R., \& Smokowski, P. R. (2017). Negative bystander behavior in bullying dynamics: Assessing the impact of social capital deprivation and anti-social capital. Child Psychiatry and Human Development, 48(1), 120-135. doi:10.1007/s10578-016-0657-0

Evans, C. B. R., \& Smokowski, P. R. (2015). Prosocial Bystander Behavior in Bullying Dynamics: Assessing the Impact of Social Capital. Journal of Youth and Adolescence, 44(12), 2289-2307.

Macháčková, H., Dedkova, L., Sevcikova, A., \& Cerna, A. (2013). Bystanders' Support of Cyberbullied Schoolmates. Journal of Community \& Applied Social Psychology, 23(1), 25-36. 
Menesini, E., Eslea, M., Smith, P. K., Genta, M. L., Giannetti, E., Fonzi, A., \& Costabile, A. (1997). Crossnational comparison of children's attitudes towards bully/victim problems in schools. Aggressive Behavior, 23(4), 245-257. doi:10.1002/(SICI)1098-2337(1997)23:4<245::AID-AB3>3.0.CO;2-J

Miller, T. W., Beane, A., \& Kraus, R. F. (1998). Clinical and cultural issues in diagnosing and treating child victims of peer abuse. Child Psychiatry and Human Development, 29(1), 21-32. doi:10.1023/A:1022679029618

Morrison, G. M., Furlong, M. J., \& Smith, G. (1994). Factors associated with the experience of school violence among general education, leadership class, opportunity class, and special day class pupils. Education and Treatment Of Children, 17(3), 356-369.

National Institute of Justice, "Understanding Cyberbullying: Developing an Evidence-Based Definition", September 9, 2016, from NIJ.gov: http://nij.gov/topics/crime/pages/understandingcyberbullying.aspx

Norwich, B., \& Kelly, N. (2004). Pupils' views on inclusion: Moderate learning difficulties and bullying in mainstream and special schools. British Educational Research Journal, 30(1), 43-65. doi:10.1080/01411920310001629965

Olweus, D. (1995). Bullying or peer abuse at school: Facts and interventions. Current Directions in Psychological Science, 4(6), 196-200. doi:10.1111/1467-8721.ep10772640

Rose, C. A., Simpson, C. G., \& Preast, J. L. (2016). Exploring Psychosocial Predictors of Bullying Involvement for Students with Disabilities. Remedial and Special Education, 37(5), 308-317.

Saylor, C. F., \& Leach J. B. (2009). Perceived Bullying and Social Support in Students Accessing Special Inclusion Programming. Journal of Developmental and Physical Disabilities, 21(1), 69-80. doi:10.1007/s10882-008-9126-4

Weiner, M. T., \& Miller, M. (2006). Deaf Children and Bullying: Direction for Future Research. American Annals of the Deaf, 151(1), 61-70.

Wolpert, S. (2010, August 19). Victims of bullying suffer academically as well, UCLA psychologists report. Retrieved April 03, 2018, from http://newsroom.ucla.edu/releases/victims-of-bullying-sufferacademically-168220 